\title{
Inductive Stirring in
}

\section{Arc Furnaces}

\author{
by Sven Fornander
}

and

Folke Nilsson

\section{(4) The Reducing Period}

$\mathbf{T}$ HE effort of the steelmaker during the reducing period in the arc furnace has been aptly characterized as a battle against oxygen. If the oxygen content of the bath can be decreased, this will contribute substantially towards a quick desulphurization and towards a cleaner steel.

In the manufacture of constructional steels of the type made in the experimental heats one to four the following practice has been applied at Surahammar for a number of years. After "slag off" an aluminium addition of about $1 \mathrm{lb}$. per ton is made to the slag-free bath. Immediately afterwards the bulk of the silicomanganese is added as well as burnt lime, fluorspar, pulverized ferrosilicon and coke powder. Carbide slags are not used. A white slag is aimed at.

Sven Fornander is Research Manager of Surahammars Bruks AB, Surahammar, Sweden, and Folke Nilsson is General Manager, Hagfors Steelworks, Uddeholms AB, Uddeholm, Sweden.

This paper was presented before the Seventh Annual Electric Furnace Steel Conference, Iron and Steel Div., A.I.M.E., Pittsburgh, Dec. 8-10.

Aluminium determinations made on mold samples, which are taken during the reducing period, show that the aluminium content of the steel bath has decreased to $\mathbf{0 . 0 0 2}$ pct A1 already $\mathbf{3 0}$ min after the addition was made. The aluminium determinations were carried out by the Metallografiska Institute by means of a spectrographic method, which was developed there ${ }^{7}$ and which has a good accuracy. It is improbable that an aluminium content as low as 0.002 pct would affect the properties of the finished steel. Therefore it can be said that by an aluminium deoxidation no new factor has been introduced in the steelmaking process, which could have an influence upon steel quality. The advantage of this practice is, that the deoxidation proceeds rapidly, at least in the beginning.

At the Uddeholm furnace all experimental heats were made without an early deoxidation. The practice applied was the same as that described by Marsh ${ }^{8}$ and by Urban and Derge ${ }^{9}$.

a-Deoxidation: Fig 15 shows the change with time of the oxygen content of the steel during the reducing period for the heats one to four. Each curve represents an average between two heats. It is obvious that the oxygen content of the steel decreases more rapidly in the heats made with inductive stirring. It can be seen from the curves that if it is intended to produce a steel of the type in question with a certain oxygen content before tapping, the time under reducing slag can be shortened by 30 to $40 \mathrm{~min}$ with the aid of the electric stirrer. For 
To his is the concluding portion of a two-part article. Last month the authors described the type of inductive equipment developed in Sweden to accelerate metallurgical reactions and speed the refining period. Herein are described factors developed during the reducing period, specific effects on refractory linings and economical aspects related to the use of the stirrer.

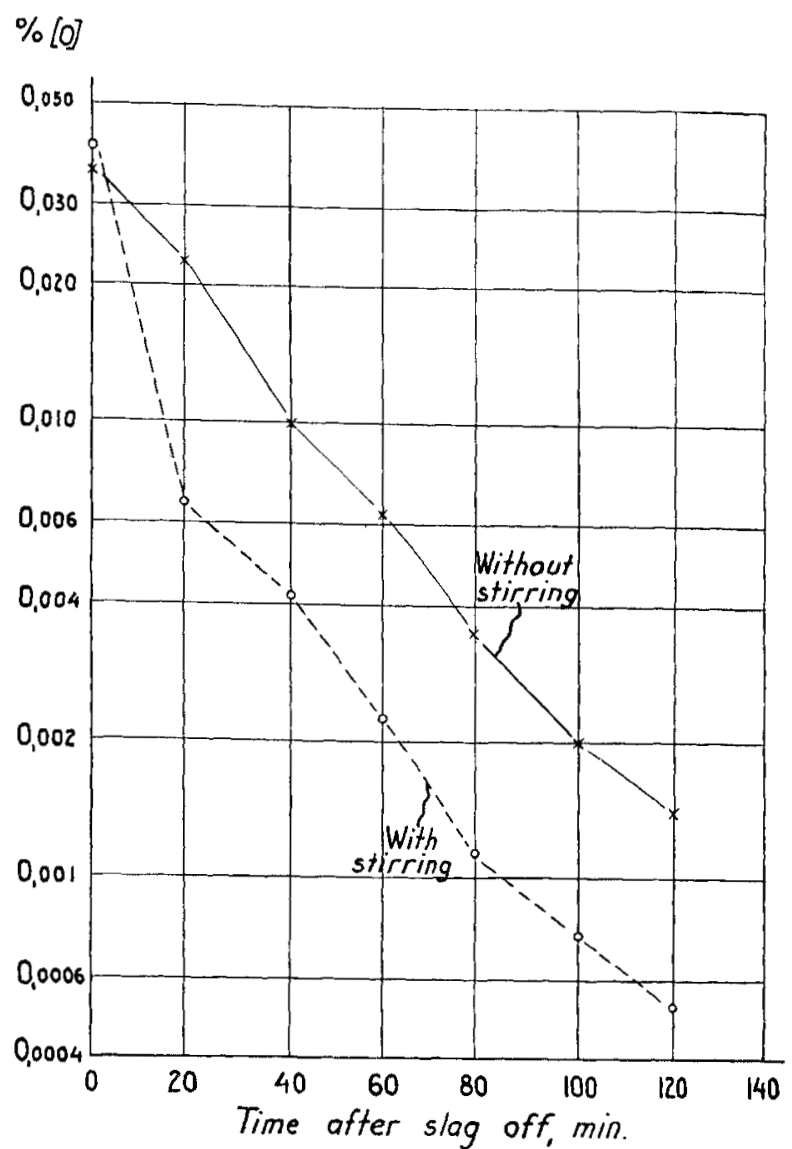

Fig 15-Deoxidation during reducing period, heats No. 1 to 4 . certain other types of steel the time saving is considerably greater, $1 \mathrm{hr}$ or even more according to experience. It should perhaps be pointed out that the oxygen contents obtained in the steel bath just prior to tapping in the heats made with stirring are lower than any, which have been reported in the literature.

The experience gained at the Uddeholm furnace points in the same direction. Fig 16 shows the change with time of the oxygen content of the steel during the reducing period for four heats made with inductive stirring as well as for four additional heats, made in a conventional way for comparison. The diagrams cover the period of time from the end of slagging off to the last sample before the additions. As will be seen from the diagrams the oxygen contents at the end of slagging off were rather different in the different cases. All the heats in which the stirrer was used had lower oxygen contents towards the end, irrespective of whether the oxygen was higher or lower than in the comparable heats at the beginning.

To estimate the gain in time to be achieved by use of the stirrer only the heat pairs 5-6 and 12-13 are suitable. In heat No. 11 the oxygen content of the last sample is about $1 / 5$ of that in the comparison heat No. 10. However, the oxygen contents at the beginning of the reducing period are so different that a comparison seems not to be justified. In the heat pair 8-7 the reducing time was too short and the FeO content of the slag too high for conclusions to be drawn. From the diagrams the conclusion was drawn that the use of the stirrer permits a shortening of the reducing time by about $30 \mathrm{~min}$ if the deoxidation only is taken into account.

Reverting to the question of how the inductive stirring promotes a more rapid and complete deoxidation the following suggestions may be advanced. When the deoxidizing agents-aluminium, silicon and manganese-have been added to the steel bath, which contains oxygen, deoxidation products are formed. These consist mainly of oxides of $\mathrm{Al}$, Si and $\mathrm{Mn}$. If the deoxidation products are finely divided, it takes time before they are removed from the bath, as they rise to the surface only slowly to dissolve in the slag. As a result of the stirring during the reducing period, perpetually "new" parts of the steel bath come into contact with the lower surface of the slag layer. Until this aspect has been studied in detail it could be assumed that, during the first part of the reducing period, the deoxidation products stick to the slag. Thus the deoxidation products are continuously washed out from the steel by the slag.

As will be seen from fig 15 the deoxidation proceeds even after the effect of the deoxidizers has ceased, published investigation $\mathbf{s}^{13}$ showing that a 

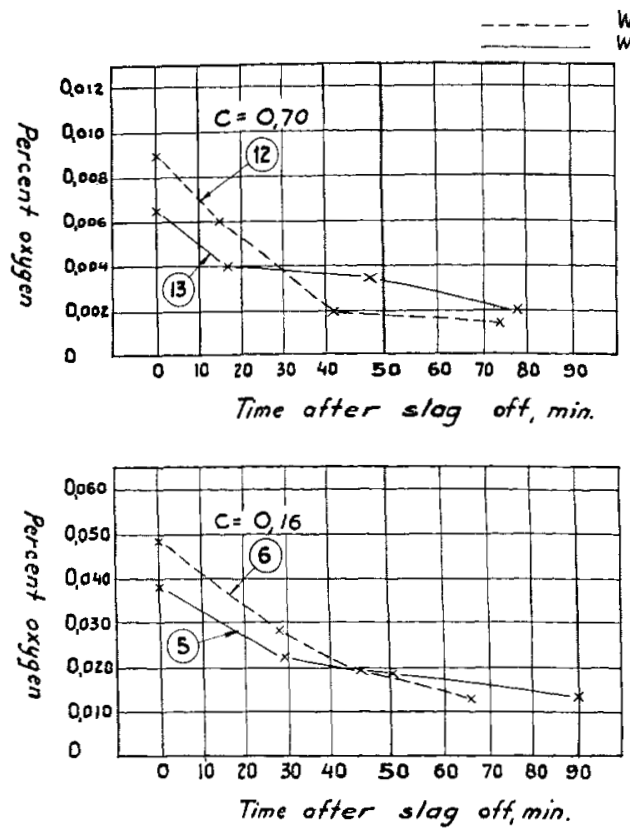

steel bath containing 0.3 pct $\mathrm{Si}$ and 0.7 pct $\mathrm{Mn}$ can hold about 0.010 pet 0 in solution. Fig 15 shows on the other hand that the oxygen contents obtained just prior to tapping are of the order of 0.001 pct 0 . Therefore it is assumed that the deoxidation which occurs during the latter part of the reducing period takes place as a result of the following circumstances. The FeO activity of the steel bath, defined in the usual way, is of the order of 0.05 at $1600^{\circ} \mathrm{C}$ if the oxygen content is 0.010 pct 0 . In the same circumstances

${ }^{7}$ G. Carlsson: "Spektralanalytisk bestämning av laga aluminiumhalter i stal" (Spectrographic Determination of Low Aluminium Contents in Steel), Jernkontorets Annaler 126, 1942, pp. 161/176.

$8 \mathrm{~J}$. S. Marsh: "Slag-Metal-Oxygen Relationships in the Basic Open-Hearth and Electric Processes", Trans. A.I.M.E. 162, 1945, pp. 672/684.

${ }^{9} S$. F. Urban and G. Derge: "Oxygen in Basic Electric-Furnace Baths", Trans. A.I.M.E. 172, 1947, pp. $196 / 211$.

${ }^{10} \mathrm{D}$. A. Oliver and T. Land, "The Temperature Distribution in the Liquid Steel in Various Steelmaking Furnaces". Journ. Iron Steel Inst. 145, 1942, pp. 245/ 277.

${ }^{11} \mathrm{H}$. Pettersson: "Tillstoindsdiagram för basiska stalslagger". (Phase Diagrams for Basic Steel Slags). Jernkontorets Annaler 132, 1948, pp. 42/56.

${ }_{12} A$, L. Bradley, J. H. Chesters, J. M. Ferguson and R. J. Sarjant: "The Basic Open-Hearth Furnace". Iron Steel Inst., Spec. Rep. No. 33, London 1946, pp.
$117 / 154$.

${ }^{13} \mathrm{~F}$. Koerber and $W$. Oelsen: "Grundlagen der Desoxydation mit Mangan und Silizium" (Fundamentals of the Deoxidation with Manganese and Silicon). Mitt. Kais,-Wilh.-Inst. Eisenforschg., Dïsseld. 15, 1933, pp. 271/309.

the FeO content of the slag is low, about 1 pct. Although no investigations have been reported on the correlation between $\mathrm{FeO}$ activity and $\mathrm{FeO}$ content for slags of this kind it seems to be justifiable to assume that the $\mathrm{FeO}$ activity is low, of the order of 0.005 . If there is to be an equilibrium between steel and slag, it is required that the
Fig 16-(Left) Deoxidation during reducing period, heats No. 5 to 13 .

Fig 1\%-(Below) Desulphurization d $u$ rin $g$ reducing period, heats No. 1 to 4 .

$\%[5]$

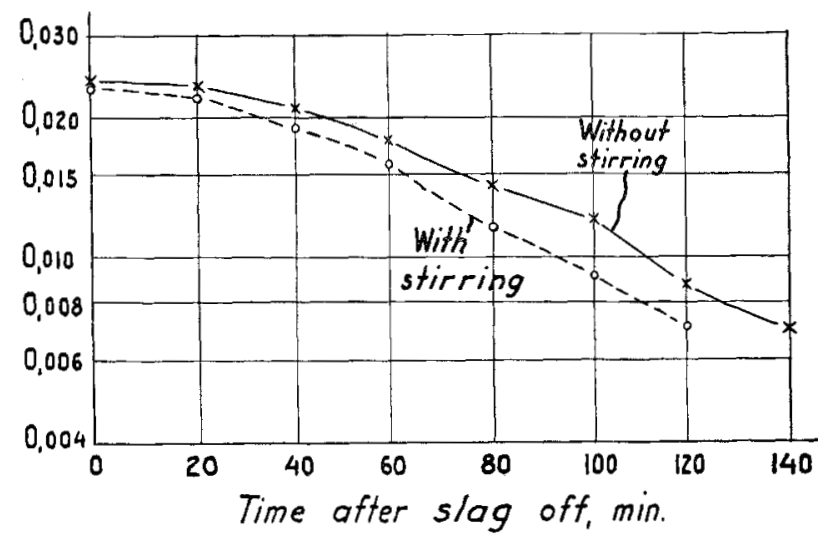

FeO activity is the same in both phases. As a result FeO has a tendency to escape from the steel bath and accumulate in the slag. In this case it is a question of a diffusion process which takes place in the surface of contact between slag and steel. The stirring can be said to enlarge this surface and for this reason a more effective deoxidation is obtained.

b-Desulphurization: Fig 17 shows the change with time of the sulphur content of the steel bath during the reducing period for the heats one to four. Desulphurization was good in both cases, when stirring was used and when it was not used. The rate of desulphurization is somewhat greater for the heats made with inductive stirring. The use of the stirrer has brought about a time saving of about $20 \mathrm{~min}$. The remark above concerning oxygen is applicable to sulphur also: for certain other types of steel the time saving is greater, up to one hour.

Table VI shows the desulphurization obtained at the Uddeholm furnace. As will be seen from the table the stirrer brings about a more rapid desulphurization. Experiments on a somewhat larger scale than recorded in the table gave the following result. When stirring was not used the 
refining time required to obtain an effective desulphurization amounted to $1 \frac{1}{2} \mathbf{h r}$. By use of inductive stirring the time could be shortened by $25 \mathrm{~min}$.

\section{TABLF VI}

Desulphurization at 15-Ton Furnace

\begin{tabular}{|c|c|c|c|c|c|}
\hline \multirow{2}{*}{$\begin{array}{l}\text { Number } \\
\text { of } \\
\text { Heats }\end{array}$} & \multirow{2}{*}{ Stirring } & \multirow{2}{*}{$\begin{array}{l}\text { Refining } \\
\text { Time, } \\
\text { Min. }\end{array}$} & \multicolumn{2}{|c|}{ Percent [S] } & \multirow{2}{*}{$\begin{array}{c}\text { Desulphur- } \\
\text { ination, } \\
\text { Pet } \mathbf{S} \\
\text { per hr }\end{array}$} \\
\hline & & & $\underset{\text { Slag }}{\text { At }}$ & $\begin{array}{l}\text { Prior to } \\
\text { Tapping }\end{array}$ & \\
\hline $\begin{array}{l}6 \\
6\end{array}$ & $\begin{array}{l}\text { None } \\
\text { Inductive }\end{array}$ & $\begin{array}{l}89 \\
87\end{array}$ & $\begin{array}{l}0.029 \\
0.030\end{array}$ & & $\begin{array}{l}0.006 \\
0.009\end{array}$ \\
\hline
\end{tabular}

As to the reason why the inductive stirring promotes a quicker desulphurization the following circumstances should be taken into account. The desulphurization takes place according to the reaction

$$
[\mathrm{FeS}]+(\mathrm{CaO})=(\mathrm{CaS})+(\mathrm{FeO})
$$

square brackets denoting that the substance is dissolved in the metal and parentheses that it is dissolved in the slag. According to this reaction the sulphur in the steel bath occurs as iron sulphide. This reacts with $\mathrm{CaO}$ in the slag, the reaction products being $\mathrm{CaS}$ and $\mathrm{FeO}$, which are both in solution in the slag. Thus, the reaction
(1) During carbon refining the temperature is the same in different parts of the bath, and this is the case irrespective of whether the stirrer is used or not.

(2) Readings taken during the reducing period and without use of the stirrer showed a maximum temperature difference of $19^{\circ} \mathrm{C}$ between the surface and bottom layers of the bath.

(3) When the stirrer was used during the reducing period, no temperature difference was recorded between the surface and bottom layers.

In taking temperature readings at the 10-ton Surahammar furnace without use of the stirring coil it was difficult to obtain reliable results during the reducing perlod. The reason seemed to be that the pyrometer could not be kept steady during the measurement. Moving a short distance, say 2 in, would in some cases result in a change of the reading by $10^{\circ} \mathrm{C}$ or more. When the stirring current was switched on, it became easy to take readings, for the temperature was then the same in various parts of the bath.

A special technique was developed to measure the temperature of the slag. The hot junction of
Fig 18-Concentrations in surface and bottom layers of the steel bath.

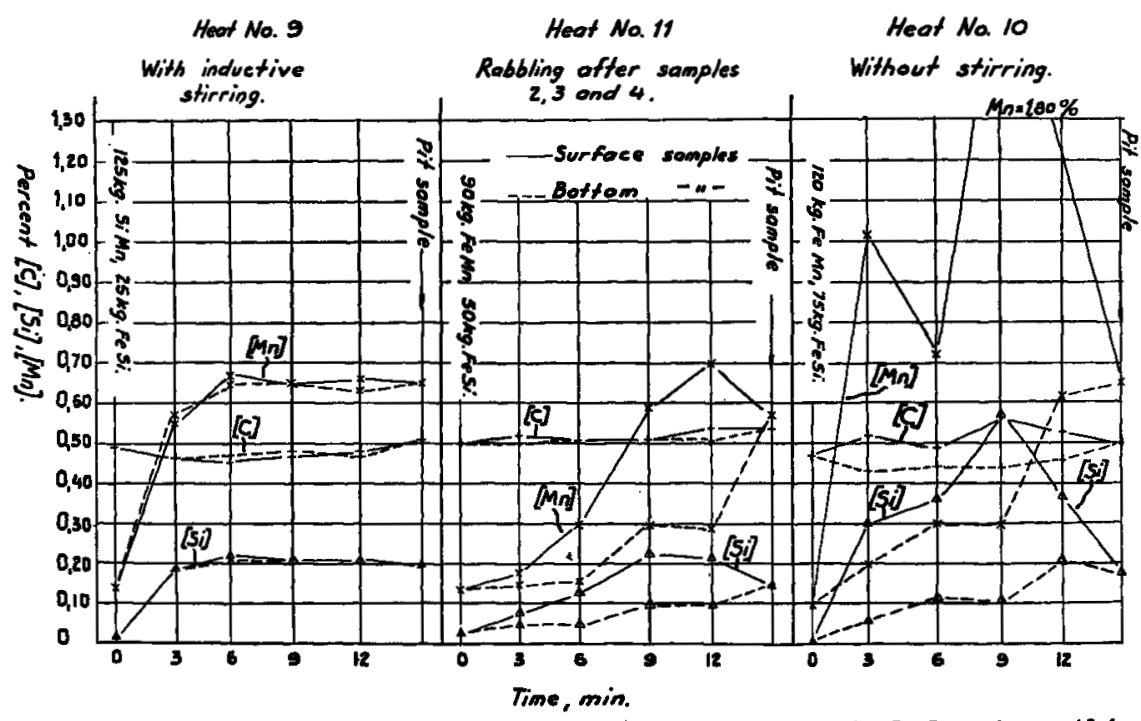

the thermocouple was protected by two thinwalled silica sheaths, one inserted into the other. To make a determination the hot junction of the thermocouple is first immersed in the steel bath, the temperature of which is recorded. To attain temperature equilibrium a somewhat longer time is required than normally: about 30 sec as compared with about 15 sec. Then the silica sheaths are placed horizontally in the slag layer. After a further $15 \mathrm{sec}$ the slag temperature is recorded. By the time the reading has been made, the outer silica sheath has usually dissolved in the slag layer, only the inner sheath remaining. Perhaps it should be added that measurements of this kind are not always successful.

The following series of measurements illustrate the importance of the inductive stirring for the heat transfer from the slag to the bath. During the whole experiment the power input to the 10ton furnace was kept constant at $3500 \mathrm{~kW}$. (The power input required to keep the bath at a constant temperature is approximately $800 \mathrm{~kW}$ ). 
Time,

min

0 Clear melt. Stirring current switched on 30 min previously. Bath carbon $=0.12$ pet. Bath quiet; no boil.

12 Steel temperature $=1610^{\circ} \mathrm{C}$. Slag temperature $=1636^{\circ} \mathrm{C}$.

13 Stirring current switched off.

$2070 \mathrm{~kg}$ iron ore $+150 \mathrm{~kg}$ burnt lime added.

25 Weak boil.

30 Steel temperature $=1620^{\circ} \mathrm{C}$. Slag temperature $=1722^{\circ} \mathrm{C}$

With this high power input to the furnace the difference between the temperatures of the slag and the steel was $26^{\circ} \mathrm{C}$ as long as the electric stirrer was in operation, and increased to $102^{\circ} \mathrm{C}$ 17 min after the stirring current had been switched off.

d-Concentration distribution: There is no reason to expect that the stirring would affect the distribution of the alloying elements in the steel bath during the carbon refining period. The bath is then homogeneous with respect to concentration and temperature.

During the reducing period conditions are different, and this is so especially shortly after alloy additions have been made. A study of these conditions was made at the Uddeholm furnace, see fig 18

Heat No. 9 was made with inductive stirring. The concentrations of the alloying elements silicon and manganese are the same in the surface and bottom layers of the bath within $6 \mathrm{~min}$ of making the additions. Heat No. 11 was thoroughly rabbled by hand three times during the first 9 min after the addition, but in spite of this there are still large differences between the concentrations in the surface and bottom layers of the bath $12 \mathrm{~min}$ after the addition. In heat No. 10, which was neither stirred nor rabbled, the differences are larger still.

This experiment has been confirmed many times in everyday practice by both of the companies that took part in this investigation. It is obvious that inductive stirring affords an exceedingly good chance to obtain a homogeneous bath shortly after additions have been made. This property of the stirrer would be used to the greatest advantage in the manufacture of highalloy steels, e.g. high speed steels and stainless steels.

(5) The furnace lining: According to the experience gained at Surahammar and at Uddeholm there is nothing which indicates that the life of the furnace bottom is affected by the electric stirrer, either favourably or unfavourably.

However, the investigations carried out by the two works have brought to the fore a question of great principal interest for steelmaking in the basic furnace, namely the role of the lining in the process. Some of the results obtained indicate that the lining gives off oxygen to the steel bath during the reducing period. The same hypothesis has previously been put forward by Marsh8.

The phase diagrams for the systems composed of the oxides of iron and the basic oxides $\mathrm{CaO}$ and $\mathrm{MgO}$ are not known in detail ${ }^{11}$. However, it is obvious that a basic furnace lining can hold in solution at $1600^{\circ} \mathrm{C}$ a considerable amount of $\mathrm{FeO}$, something between 10 and 30 pct $^{12}$. Therefore the quantity of oxygen in form of $\mathrm{FeO}$, which can be absorbed by a furnace bottom is many times greater than that dissolved in the steel.

Thus there is a good reason to study in rather more detail the effect of the furnace lining upon the course of the reactions taking place in the basic steel furnace. It is to be hoped that coming investigations will clarify this question.

Economical aspects: It will not be possible to make a generally applicable calculation of the savings which can be made by the installation of an electric stirrer. The profit obtained will depend upon the local conditions at the steelworks in question, and it can be stated only when these conditions are known.

At the two works which took part in this investigation experience has shown that the installation of the electric stirrer is well warranted from an economic point of view. In the authors opinion Dr. Dreyfus invention is one of the most valuable contributions made to the development of the arc furnace since its introduction in the steel industry 50 yrs ago. It is delicate to make predictions but it would not be surprising if the electric stirrer would in the future be regarded as the one device, which the arc furnace needed to allow it to compete successfully with other types of furnace as far as large-scale production of quality steels is concerned.

Summary: During $1 \frac{1}{2}$ yr operation of ASEA electric stirrers on arc furnaces the following information was gathered at two Swedish steelworks.

The inductive stirring has no influence upon carbon refining at high or medium carbon contents. In the production of low-carbon steels the stirring makes it possible to attain lower carbon contents. In spite of this the oxygen content of the steel is lower and the FeO content of the slag lower than in conventional practice.

The slagging-off operation is considerably facilitated by the stirring and can be carried out more effectively than in normal practice. Oxidizable impurities, e.g. phosphorus and chromium, can be removed effectively.

The reactions occuring between steel and slag during the reducing period are accelerated. Extremely low oxygen contents can be attained. The reducing time can be shortened.

The differences in temperature and concentration in the bath during the refining period are equalized by the inductive stirring. The heat transfer from the arcs to the steel bath is facilitated.

The installation of the stirrer is well warranted from an economic point of view.

Acknowledgments: The authors wish to express their thanks to E. Améen, Managing Director of Surahammars Bruks AB, and N. Danielsen, Managing Director of Uddeholms $A B$, for their kind permission to publish this paper. They also wish to acknowledge the efforts of Messrs S. Bergström, L. Bjerkerud, N. Olsson and B. A. Quick and to thank them for their helpful assistance in carrying out the experiments and oxygen determinations. 